\title{
Second Pharyngeal Pouch
}

National Cancer Institute

\section{Source}

National Cancer Institute. Second Pharyngeal Pouch. NCI Thesaurus. Code C34289.

A paired evagination of embryonic pharyngeal endoderm, which is located between pharyngeal arches two and three, and which contributes to the formation of the middle ear and palatine tonsils. 